\title{
The changing relationship between prescribing and unemployment at family health service authority level in England, 1983-92
}

\author{
David C E F Lloyd, Glen Scrivener
}

\begin{abstract}
Study objective-To investigate the relationship between unemployment and prescribing costs over time.

Design-This was a longitudinal study. Setting-All 90 family health service authorities in England, 1983-92.

Participants-All general practices in England.

Main results-The strength of the relationship varied over the period, falling to a very low value during the last two years of the decade.

Conclusion-Unemployment rates are not suitable as a proxy for the determinants of prescribing costs.
\end{abstract}

( $\mathcal{F}$ Epidemiol Community Health 1997;51:383-385)

Most commentators would accept that demography has a large influence on prescribing. Forster and Frost ${ }^{1}$ found that age and sex (proportion of males aged 75 years and over and proportion of females 65-74 years) explained $44 \%$ of the variation in cost per patient between family health service authorities (FHSA), the organisations responsible for the provision of primary care. However, it is clear that this is not the only influence. The pattern of local variations in morbidity may have an effect, but data on this is almost impossible to obtain for any other than the relatively small sample of practices in the national morbidity survey. ${ }^{2}$ The 1991 census asked respondents about limiting long term illness, but this only measures illness of a severe and prolonged nature and so is only the tip of the morbidity iceberg. Limiting long term illness is also closely associated with age, ${ }^{3}$ and so is unsuitable where we wish to account separately for demography, and it is only available for 1991. Many authors have proposed the use of deprivation, however measured, as a proxy for morbidity. ${ }^{4-9}$ Many of the measures of deprivation that might be suitable are only available from the decennial census and so some authors have proposed using unemployment rates, ${ }^{1011}$ which are available at frequent intervals. We considered that the relationship between unemployment and prescribing was not likely to be stable given the fact that the nature of unemployment has changed in recent years as traditionally affluent areas have experienced increasing levels of unemployment and many administrative changes have been made in the definitions used in the unemployment figures produced by the Department of Employment. ${ }^{12}$ Accordingly, we investigated the relationship between prescribing costs and unemployment rates for English FHSAs over a 10 year period.

\section{Method}

The figures on costs and number of patients for all ninety FHSAs in England were obtained from PD1 reports prepared by the Prescription Pricing Authority for the years 1983-92. Costs were used since the number of items can be affected by factors such as the duration of prescriptions. The cost we used is known as "basic cost" and excludes such things as container costs and dispensing fees. The PD1 reports relate only to items dispensed by a community pharmacist and so the number of patients used does not include dispensing patients. The numbers of dispensing patients are small compared with the number of nondispensing patients (about $6 \%$ of the total) and so we did not feel concerned at their exclusion.

The unemployment rate used by the Department of Employment is defined only for self contained labour markets. These are usually "travel to work areas", defined by the department, or counties. The rate compares persons claiming unemployment benefit with the sum of these claimants and the number of employees as estimated by the department. Although the numbers of unemployed are available for all the authorities, only half of them meet the self containment criteria and have rates calculated by the Department of Employment. There are problems of interpretation if any attempt is made to use rates at a lower level. ${ }^{13}$ Rates calculated for areas that do not meet the self-containment criteria could be misleading. For example, the City of London district had a resident population of 4000 in 1989 but 310900 persons were employed there and it is this figure on which the Department of Employment unemployment rate would be calculated.

While we were aware of the dangers mentioned above, to carry out an analysis for all 90 authorities it was necessary to calculate our own unemployment rate whether or not the area fulfilled the department's criteria. We used the numbers of unemployed as given by the department. The population bases we used were the mid-year estimates produced by the Office of Population Censuses and Surveys to give a figure approximating the population of working age (males 15-64, females 15-59). Since the data are supplied in 5 year age bands it was necessary to use 15 as the starting age 


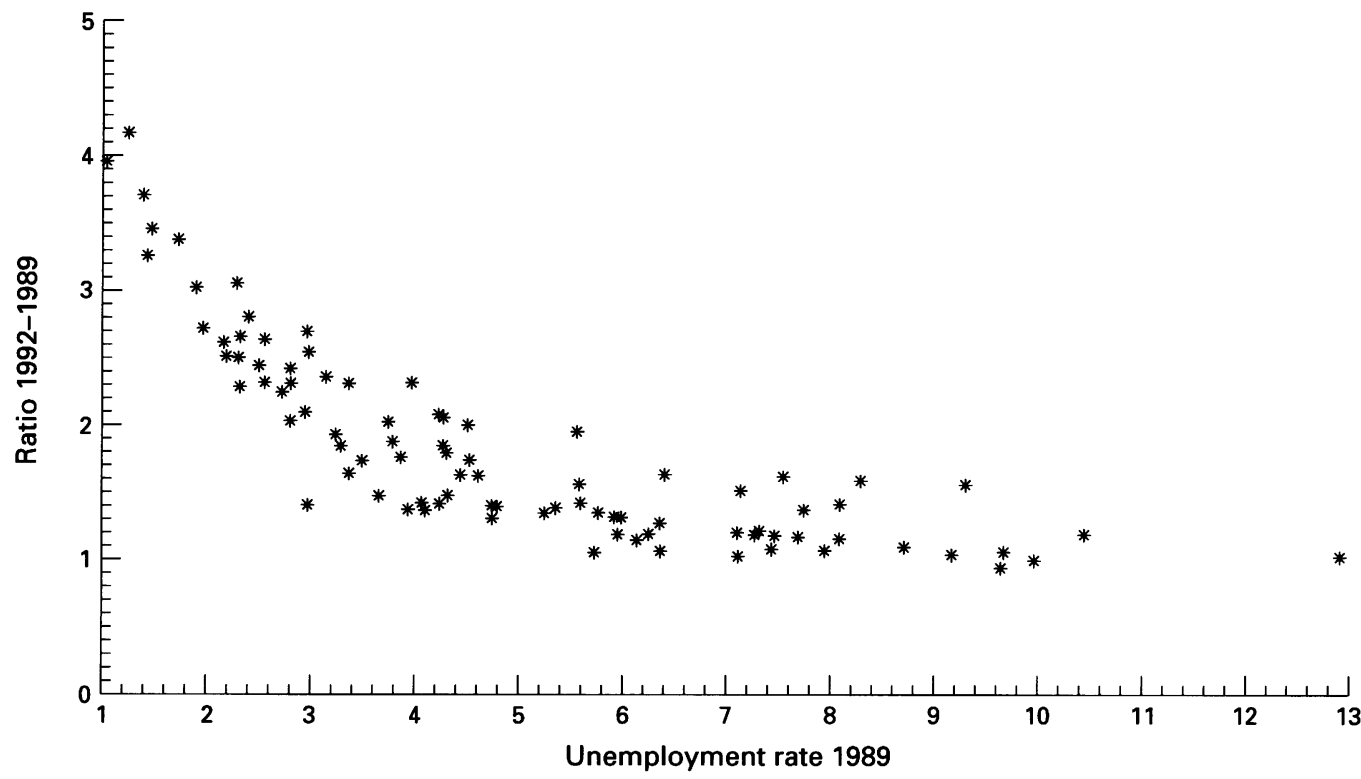

Figure 1 Ratio of 1992 unemployment rate to 1989 unemployment rate for 90 family health services authorities against the 1989 unemployment rate.

Table 1 Correlation between the Department of Employment unemployment rates and the authors' definition for the 45 family health services authorities which are counties and the adjusted percentage variance in basic cost/patient explained by the authors' definition of unemployment rate for all 90 authorities

\begin{tabular}{llc}
\hline Year & Correlation & \% explained \\
\hline 1983 & 0.83 & 7 \\
1984 & 0.87 & 8 \\
1985 & 0.89 & 9 \\
1986 & 0.89 & 11 \\
1987 & 0.91 & 12 \\
1988 & 0.93 & 12 \\
1989 & 0.95 & 13 \\
1990 & 0.95 & 8 \\
1991 & 0.92 & 0 \\
1992 & 0.89 & 0 \\
\hline
\end{tabular}

rather than 16 . Our base population is somewhat larger than that used by the Department of Employment as it includes everyone, regardless of economic status, and the proportion of economically inactive adults (who should ideally be excluded) may vary between authorities. To check the validity of our measure we took the 1991 census measure of unemployment (percentage of economically act-

\section{KEY POINTS}

- There are serious methodological problems in using Department of Employment unemployment rates at family health service level.

- Unemployment (as measured by Department of Employment rates) has shown marked changes in its relationship to prescribing costs over the period 1983-92.

- Because of these changes it is not a suitable explanatory variable for differences in prescribing cost.

- There seems to be remarkable stability from year to year in costs suggesting that any differences are due to factors which are very slow to change. ive residents of working age who describe themselves as unemployed) and correlated it with our measure for 1991 . We also examined the correlation between our definition and the Department of Employment's definition for the 45 FHSAs where this was possible for each year.

We also examined the stability of cost per patient over time by examining the correlation of each year's figure with the value for the following year. This gave us some idea of how much this figure was changing in relation to changes in possible drivers.

\section{Results}

The correlation between our definition of unemployment for 1991 and the value in the 1991 census was 0.98 . The correlations year by year of our definition with the Department of Employment's figures are shown in table 1 and show a significant association for each of the 10 years studied $(p<0.005)$

Table 1 also shows the adjusted percentage of variance in basic cost per patient explained by our definition of unemployment in the 90 authorities for each year. In all years except 1991 and 1992 the unemployment rate is significantly correlated with basic cost per patient $(\mathrm{p}<0.005)$

For each year from 1984-92 we found over $98 \%$ of the variation in basic cost per patient was explained by the figure for the previous year.

\section{Discussion}

These significant correlations found suggest that our measure is well correlated with both the Department of Employment measure and the census (which use very different definitions of unemployment) and suggest that any error in our measure caused by the slight mismatch in age groups and the impossibility of excluding 
the economically inactive was not a serious problem.

The link between unemployment and cost per patient is not strong. Even when there was a significant correlation, unemployment explained only a limited amount of the variation. The decline in the strength of the association from 1989 onwards was associated with increasing unemployment in areas which had traditionally had low levels of unemployment. Figure 1 shows that the increase, as measured by the ratio of the unemployment rate in 1992 to the unemployment rate in 1989, was much greater in areas of low unemployment than in areas of high unemployment. It has been suggested that the fear of impending unemployment is as great a factor as actual unemployment ${ }^{14}$ in influencing prescribing costs and so actual rates may be a poor indicator when employment is rising.

Pringle and Morton-Jones ${ }^{10}$ found a correlation of 0.524 between cost per person and the unemployment rate for 1989 , while we found the correlation to be only 0.36 . There are several differences in the data used in their study and our own. They took the net ingredient cost for the financial year 1989/90 and divided it by the number of persons estimated by the Office of Population Censuses and Surveys to be resident in the area. We took the basic nondispensing cost for the calendar year 1989 and divided it by the number of registered nondispensing patients. They obtained the numbers of unemployed from Regional Trends which gives the numbers of unemployed in January, while we took the figure for June as being midway through the calendar year. Since our figures are consistently defined for the period considered we feel that these differences do not change our central conclusion, which is that the link between unemployment and cost of prescribing changed so substantially after 1990 that unemployment cannot be regarded as a valid proxy for prescribing need.

We found a high degree of stability in cost per patient between one year and the next. Since this figure differs widely between authorities it seems clear that each has an individual character which largely determines the value. The 1983 cost per patient explained $76 \%$ of the variation in the 1992 figure, again emphasising the stability in the relative costs of the authorities. This casts doubt on the ability of any measure which changes rapidly to explain these differences.

\section{CONCLUSION}

During the period 1983-92 unemployment has been an indifferent predictor of differences between FHSA's prescribing costs. What success it had in the early and middle years was probably due to its acting as a marker of more fundamental differences between areas. However, more recent changes in the nature of unemployment (or in the way in which it is measured $^{12}$ ) have made it less useful. The high correlation between costs year upon year suggests that any variable which is linked to differences between authorities must possess a good degree of stability.

The 1991 Census data are Crown Copyright, ESRC purchase. The OPCS mid-year estimates are Crown Copyright.

Funding: The Prescribing Support Unit is funded by the Department of Health.

We would like to thank the Prescription Pricing Authority for making the PD1 reports available to us and thank NOMIS for providing the information on the numbers of unemployed.

providing the information on

1 Forster DB, Frost CEB. Use of regression analysis to explain the variation in prescribing rates and costs between family practitioner committees. Br f Gen Pract 1991;41:67-71.

2 Royal College of General Practitioners, Office of Population Censuses and Surveys, Department of Health and Social Security. Morbidity statistics from general practice: 3nd naSecurity. Morbidity statistics from general practice: 3rd na-
tional study, 1981-82. London: HMSO, 1986. Series MB5 tional 1 .

3 Scrivener G, Lloyd DCEF. Two proxies for morbidity in the 1991 UK Census: permanent sickness and limiting long-term illness. $\mathcal{F}$ Epidemiol Community Health 1996;50 223.

4 Black D. Inequalities in health: report of a working group. London: HMSO, 1980.

5 Townsend P, Simpson D, Tibbs N. Inequalities in health in the city of Bristol: preliminary review of the statistical evidence. Int $\mathcal{f}$ Health Serv 1985;15:637-63.

6 Marsh GN, Channing DM. Deprivation and health in one general practice. $B M \mathcal{F}$ 1986;292:1173-76.

7 Whitehead M. The health divide: inequalities in health in the 1980s. London: Health Education Authority, 1987.

8 Townsend P, Phillimore P, Beattie A. Health and deprivation inequality and the north. London: Croom Helm, 1988.

9 Carstairs V, Morris R. Deprivation, mortality and resource allocation. Community Med 1989;11:364-72.

10 Pringle M, Morton-Jones A. Using unemployment rates to predict prescribing trends in England. $\mathrm{Br} \mathcal{F}$ Gen Pract 1994;44:53-56

11 Campbell DA, Radford JMC, Burton P. Unemployment rates: an alternative to the Jarman Index. $B M \mathcal{F} 1991 ; 303$ 750-55.

12 Working Party on the Measurement of Unemployment in the UK. The measurement of unemployment in the UK fournal of the Royal Statistical Society A 1995;158:363-417. 13 Employment Gazette Occasional Supplement No 3, September 1984;92:9.

14 Beale N, Nethercott S. Job loss and family morbidity: a study of factory closure. $7 R$ Coll Gen Pract 1985;35: 510-14. 